\title{
LOURO, Guacira Lopes. Um corpo estranho: ensaios sobre sexualidade e a teoria Queer. Belo Horizonte: Autêntica, 2008.
}

\section{Arilda Ines Miranda Ribeiro ${ }^{1}$}

No Brasil, de acordo com alguns autores das ciências sociais, pelo menos até 2004, não se institucionalizou uma área de estudos gays e lésbicos e mais do que isso, nem uma linha de teoria e pesquisa que poderíamos denominar de queer, na forma que tem acontecido nos EUA e na Europa.

Raríssimas exceções estão contidas no campo dos estudos literários e na educação. Indiscutivelmente os trabalhos de Guacira Lopes Louro na problematização de uma pedagogia queer contribuem para desestabilizar os grupos acadêmicos conservadores ao evidenciar as chamadas minorias sexuais, que hoje, felizmente, são muito mais visíveis do que antes.

Licenciada em História pela Universidade Federal do Rio Grande do Sul, Mestre em Educação pela mesma Universidade Federal do Rio Grande do Sul e Doutora em Educação pela Universidade Estadual de Campinas, é atualmente professora titular aposentada da Universidade Federal do Rio Grande do Sul. Colaboradora convidada desta mesma universidade atua no Programa de Pós Graduação em Educação, na Linha de Pesquisa Educação, Sexualidade e Relações de Gênero. Foi fundadora do GEERGE (Grupo de Estudos de Educação e Relações de Gênero) e participa deste grupo de pesquisa desde 1990. Suas atividades de pesquisa e de orientação de dissertações e teses se voltam para o campo da Educação, com ênfase nas questões de gênero, sexualidade, e teoria queer.

A obra é irreverente e incita a transgressão do discurso complexo da Academia. Disposta em um livrinho anatômico, costurado em folhas amareladas e escrito em letras garrafais, de cara dá ao leitor a sensação de que encontrará liberdade, prazer e pertubação na leitura de novas descobertas.

Composto por quatro textos (Viajantes pós-modernos, uma política pósidentitária para a educação, "Estranhar" o currículo e Marcas do corpo, marcas

1 Doutora e Livre-Docente em Educação pela Universidade Estadual de Campinas/ Universidade Estadual Paulista (UNICAMP/UNESP); Professora Titular da Pós-Graduação e do Departamento de Educação da Faculdade de Ciência e Tecnologia da Universidade Paulista (FCT/ UNESP) de Presidente Prudente. Coordenadora do NUDISE - Núcleo de Diversidade, Brasil. Email: arilda@fct.unesp.br. 
do poder) oriundos de palestras, mesas-redondas e como afirma Louro, "lidos por um punhado de amigos e amigas, colegas e estudantes" têm em comum o dom teórico da provocação, do embaraço, da desestabilização das certezas, acrescentado de pitadas de traços literários.

Mas o que é ser queer? Do que tratam os estudos queer?

A autora nos pega pela mão, para enveredar pelas inúmeras traduções que a palavra inglesa queer pode sugerir na língua portuguesa. Não há tradução para essa palavra. Há sim, entendimentos sobre seu sentido. Queer durante muitos anos funcionou como insulto, xingamento para sujeitos não heterossexuais: gays, lésbicas, transgêneros, travestis, entre outros. O interessante nessa história é que foram esses mesmos sujeitos que assumiram a palavra queer para identificá-los como bizarros, estranhos, esquisitos, mas fundamentalmente para representar "a diferença que não quer ser assimilada ou tolerada". Ou seja, pertubar, transgredir, desestabilizar é o mote dos sujeitos que se sentem queer.

Guacira mergulha fundo no seu diálogo com teóricos norte-americanos da corrente dos Estudos Culturais com o pós-estruturalismo francês, onde é possível afirmar que o sujeito é sempre visto como provisório, circunstancial e cindido.

A base para os estudos sobre a teoria queer está contida nas obras clássicas de Michel Foucault, Jacques Derrida, Deleuze, Judith Butler, nos livros dos brasileiros Tomaz Tadeu da Silva e João Silvério Trevisan, entre outros de importância equivalente, citados ao transcorrer dos artigos de Guacira.

Por exemplo, no primeiro texto "Viajantes pós-modernos" a autora resgata o filme de Cacá Diegues, Deus é brasileiro para afirmar que nossa vida, desde o nascimento até a morte, é uma viagem. Imagem sempre evocada na Literatura e na Educação. Não há lugar de chegar, não há destino pré-fixado. Nesse sentido, o que importa é o trajeto, o movimento, as mudanças, os atalhos que traçamos. Remete a James Clifford para pensar as culturas como lugares de passagem.

Ao evocar a frase de Butler: "É um menino! É uma menina" argumenta em seu ensaio que o ato da nomeação supõe o sexo como um "dado" anterior à cultura e lhe atribue um caráter imutável, a-histórico e binário. Diante disso, afirma que não se pode fugir da ordem prevista pela sociedade: querendo ou não, os sujeitos ficam acorrentados a essa nomeação.

Não se sabe porque alguns sujeitos desobedecerão a essa normatividade social, rompendo regras. Deliciosamente transgredirão o que estava prédeterminado. Tal como umas viagens imprevisíveis, sairão da rota, subverterão atrevidamente o que lhes estava determinado realizar, cruzarão as fronteiras. Esses sujeitos queer serão os alvos preferidos das pedagogias corretivas que tentarão recuperá-los ou se for o caso, puní-los, baní-los. Um trabalho pedagógico contínuo e repetitivo será acionado para que marquem nos corpos, sobretudo os mais frágeis, para inscrever "o gênero e a sexualidade "legítimos"!! 
Como nômades, entretanto, os queer viverão perigosamente suas identidades transitórias, escancarando a construtividade dos gêneros. Como exemplo, Louro cita a drag queen, em sua imitação do feminino.

O segundo texto, "Uma política pós-identitária para a Educação" trás uma contribuição importante para aqueles que se interessam pelo percurso histórico e teórico da homossexualidade, sua criação discursivamente produzida e transformada em questão social relevante, basicamente no seu sentido moral. Em pinceladas históricas, a autora gaúcha cita os discursos de organização dos grupos homossexuais da década de 1970, o Movimento de Libertação Homossexual no Brasil no ano de 1975, a inserção da temática como questão acadêmica em idos de 1980, atropelada pelo aparecimento da Aids e da concentração nos discursos da prática do "sexo seguro".

Quando a política da identidade homossexual estava em crise, na década de 1990, surgiam proposições teóricas pós-identitárias e a teoria queer. Parafraseando Louro, "queer pode ser vinculada às vertentes do pensamento ocidental contemporâneo que, ao longo do século XX, problematizou noções clássicas de sujeito, identidade, de agência, identificação". Evoca Foucault e Butler como alavancadores de um novo foco nas estratégias de análise, advindas de outra perspectiva epistemológica, voltada para estruturas lingüísticas ou discursivas e seus contextos institucionais. Uma pedagogia queer, nesse sentido, se distinguiria de programas multiculturais bem-intencionados, tolerantes com as diferenças de gênero, sexuais e étnicas. A educação precisaria questionar a polarização hetero/homo, além do avanço no combate a homofobia.

"Estranhar o currículo" é um artigo que remete a trajetória acadêmica da autora, quase uma autobiografia, onde divide com o leitor a necessidade do espaço escolar ser local de reflexão sobre as diversas formas de viver a sexualidade, formas de ser, formas de experimentação do prazer e do desejo. Também lhe interessa compreender como ocorre a oposição binária heterossexualidade e homossexualidade nas instâncias pedagógicas. Estranhar seria como desconfiar do currículo que está posto, olhar de mau jeito o que está dado.

Finalmente no artigo "Marcas do corpo, marcas do poder" louro evoca Butler, Laqueur, Vencato, Nicholson para nos lembrar que os corpos vem sendo "lidos" de formas distintas em diferentes culturas. O modo como o binarismo masculino/feminino vem sendo entendido diverge e se modifica histórica e culturalmente (p.76) Resgata historicamente que até o início do século XIX, persistira o modelo sexual que hierarquizava os sujeitos ao longo de um único eixo (o masculino). Nas décadas finais do século XIX, médicos, filósofos, moralistas e pensadores fazem suas "descobertas" e a partir dos seus preceitos "autorizam" e "estabelecem" práticas sexuais. Produzem discursos, classificam, disciplinam, através de suas autoridades, os corpos. Nesse sentido, se transformam em mar- 
cas de poder, em relação de poder. Exemplifica a drag como aquele corpo que transgride e subverte o feminino, salientando os códigos culturais que marcam esse gênero. Ao brincar com esses códigos, através de sua forma estranha (queer) e bizarra, ajuda-nos a lembrar que nossas marcas no corpo foram inventadas e culturalmente sancionadas em nossa sociedade.

Ler Um corpo estranho sem sombra de dúvida incomoda nossos parâmetros, atiça a dúvida, as práticas sociais cotidianas, o conhecimento e as relações entre os sujeitos. Guacira Louro, para essa resenhista, foi muito queer ao escrever seus quatro artigos: estranhos, bizarros, excêntricos, libertos das amarras acadêmicas.

Texto recebido em novembro de 2009.

Texto aprovado em junho de 2010. 


\section{ONDJAKI. Bom dia camaradas. Rio de Janeiro: Agir, 2006.}

\section{Henrique Evaldo Jansen ${ }^{1}$}

Assumidamente de fundo autobiográfico, em um texto marcado pela nostalgia, Ondjaki, jovem autor angolano, nos conduz no romance Bom dia camaradas (2006), pela Luanda de sua memória, recorrendo a um autornarrador adulto que percebe o mundo pelo olhar infantil, segundo Mia Couto, "desengaiolar sentimentos". Sob esta lente, as lembranças são orientadas pelas experiências na família, pelos "ecos" da guerra civil angolana (estão lá direta ou indiretamente indicados a MPLA, a UNITA, os "tugas" etc.) e principalmente pela experiência escolar.

$\mathrm{Na}$ escola, que desempenha o papel emblemático de sintetizar os ritos de passagem pelos quais o protagonista passa, professores cubanos cumprem um papel central na formação do herói, pois mesmo que em muitas situações do cotidiano eles sejam descritos com ironia, o que prevalece no romance é um sentimento de gratidão.

Mas não são só os professores que desempenham um papel relevante na formação do menino. Pais e outros personagens (o "camarada António", a tia Dada etc) assumem de maneira clara ou velada o papel de mentores que auxiliam o herói no processo de autodescobrimento e de orientação no mundo. Esses e outros elementos, que serão apontados posteriormente no texto, nos permitem inscrever essa obra no gênero romance de formação (também denominada por Bakhtin, romance de educação). O romance de formação - em alemão, Bildungsroman - pode ser inscrito na genealogia do paradigmático Os anos de aprendizado de Wilhelm Meister, escrito por Goethe no final do século XVIII. Para Goethe, a formação ( $c f$. KAYSER 1970) é um processo de livre desenvolvimento que é limitado apenas pela vida. Por esta razão, os seus romances podem louvar o poder da formação que se processa a partir de experiências e contatos com as pessoas do campo, da nobreza, do mundo das artes (teatro) etc. Em contraposição a essa natureza de desenvolvimento, a formação dos heróis dos Bildungsromane da virada do século XX, e, em parte, dos atuais, dá-se, basicamente, pela educação institucional. Nesse período, segundo Kay-

1 Professor Doutor do Departamento de Teoria e Prática de Ensino, do- Setor de Educação, da Universidade Federal do Paraná ( UFPR), Brasil. E-mail: henrijan@uol.com.br 
$\operatorname{ser}^{2}$ (1970) "todos tiveram que, ao contrário de Goethe, sentar diariamente nas cadeiras escolares [...]”. Se na virada do século XX, os romances de formação focalizavam, de forma predominante, a educação formal nas instituições de ensino, nos romances de formação contemporâneos, os espaços de formação se projetam sob um escopo físico mais amplo. A família, a sociedade, os amigos, as cidades (além da escola é claro) exercem um papel determinante na formação do protagonista.

Também transitando por essas esferas sociais, Ondjaki, com traços realistas, ocupa-se do herói no seu processo de transformação, pois esse, a partir de suas experiências e contatos com as posturas e valores dos outros, sequenciado por certo isolamento ( $c f$. JAKOBS, $1989^{3}$ ) no qual procura compreender as experiências vivenciadas, busca adquirir uma consciência do mundo ( $c f$. FREITAG, 2001) $)^{4}$.

Essa conscientização está interligada, como já indicado, a um processo de autodescobrimento de orientação no mundo. Tal movimento pode ser ilustrado, no romance, através de um diálogo que mantém com a colega de escola, e por quem nutre uma afetividade infantil/adolescente, a Romina (ou, Ró).

- [...] Sabes o que minha avó diz, Ró?

- Não...o que ela diz?

- Que quando vivemos os melhores tempos da nossa vida, nós nunca nos percebemos... - aí olhei para ela. -

- Mas eu acho que não é bem assim...

- Então?

- Eu sei perfeitamente que estes são os melhores tempos de nossa vida, Romina... Esta correria, estas conversas que nós temos aqui no pátio [...] (Bom dia camaradas, p. 92-93).

A aventura erótica ou afetiva (mesmo que apenas intelectualizada) constitui-se como elemento estruturante nos romances de formação. Na obra Bom dia camaradas, essa experiência é vivenciada com a Romina. Na descrição dessa personagem, duas perspectivas se sobrepõem: o encantamento visto pela lente do menino e a nostalgia percebida pelo olhar do narrador/autor adulto.

2 KAYSER, H. C. Bild und Funktion der Schule in der Deutschen Literatur um die Wende zum Zwanzigsten Jahrhundert. Waschington University, Ph.D., 1970.

3 Jacobs, Jürgen u. Krause, Markus. Der deutsche Bildungsroman: Gattungsgeschichte vom 18. Bis zum 20. Jahrhundert. München, Beck, 1989.

4 FREITAG, B. O Indivíduo em formação. São Paulo: Cortez, 2001. 
Nostalgia essa (ou perspectiva da saudade que há de vir), que também é vivenciada, no final do ano letivo, na escola. O menino já sabe que, no próximo ano, não encontrará muitos dos atuais colegas e amigos (o contexto mais amplo da conversa com a Romina, no pátio, é esse...). Aprender, como rito de passagem, a conviver com as ausências e as perdas faz parte da jornada formativa do herói. A percepção da perda também está presente na despedida dos professores cubanos que retornarão ao seu país. Em uma festa de despedida, o autor em diálogo bem humorado com o discurso do professor Angel rememora alguns desses momentos. "Quando o filme acabou, é que foram elas: eu bem que tinha sentido o cheiro de despedida, porque despedida tem cheiro, vocês sabem, né? Tanto quando acabou o filme o camarada Angel quase conseguiu recusar o pires de compota que a mãe da Ro lhe ofereceu [...]". (p. 111). Ironizando a não recusa das guloseimas e dialogando com o discurso inflamado/revolucionário do professor, o menino se aproxima de questões políticas (outro elemento, além da inserção na vida pública, central nos romances de formação):

Sobre todo, queríamos decirles, a ustedes que non son más que niños angoleños, a ustedes que son alumnos de uma escuela, y a ustedes que son nuestros amigos, que la lucha, la revolución, nunca termina: la educación es uma batalla. [...] (Nós estávamos bem espantados... Espírito revolucionário? Eu nem gostava de acordar cedo, todos nós cabulávamos em quase todas as freqüências...). (Bom dia camaradas, p. 112).

Sintomático, nesse contexto, é a relação que se estabeleceu, também fora do ensino formal da escola com os professores cubanos, pois estes são convidados, em diversas ocasiões, para encontros sociais na casa da Romina. Ela percebe/ intui - mais do que os meninos - o valor desses professores e demonstra adimiração/gratidão pelo papel que desempenharam na história angolana: “- Já viste o que é, vir para um país que não é deles, vir dar aulas ainda vá que não vá, mas aqueles que vão pra frente de combate...Quantos angolanos é que tu conheces que iam para Cuba lutar uma guerra cubana?" (Bom dia camaradas, p.77)

O discurso revolucionário dos professores cubanos é relativizado no romance pelas vozes de outras personagens que participam na construção da visão de mundo (Weltanschauung) do menino. Ilustrativamente, indicamos algumas situações.

Com bom humor pai e filho brincam com os jargões impostos pelo sistema vigente: "Bom dia, camarada pai!" disse a brincar, porque o camarada António ainda não tinha chegado. "Bom dia, camarada filho!", respondeu-me, 
bem disposto como sempre de manhã ele estava" (Bom dia camaradas, p.79). Em outro cenário, em uma conversa matinal com o camarada Antônio (cozinheiro da casa), o confronto de visões políticas aflora:

- Menino, no tempo do branco não era assim... Depois, sorria. Eu mesmo queria era entender aquele sorriso. Tinha ouvido histórias incríveis de maus tratos, de más condições de vida, pagamentos injustos, e tudo mais [...] Mas, Antônio... tu não achas que cada um deve mandar em seu país? Os portugueses tavam aqui a fazer o quê? [...] Ê!, menino, mas aquele tempo a cidade estava mesmo limpa...tinha tudo, não faltava nada...[...] - Mas ninguém era livre, Antônio...não vês isso? (Bom dia camaradas, p. 17-18).

Um outro encontro importante acontece com a tia Dada, vinda de Portugal. Ela faz o papel de mentora (como visto, a atuação de mentores é constitutiva do romance de formação...) - principalmente ao trazer informações de Portugal - contrapondo à visão interna que o herói tem de Angola, com situações e experiências trazidas de Portugal. Esses diálogos, a partir do olhar de fora (Portugal), causam estranhamento ao menino e o impelem a reorganizar alguns valores que estavam - basicamente - centrados em suas experiências e vivências em Angola. Nesse contexto, ele percebe, por exemplo, que nem todas as pessoas precisam de cartões de racionamento para adquirir produtos de consumo.

Representativo também, na produção de novos sentidos em relação a questões políticas e sociais, é a reflexão em torno da guerra, pois questiona se as pessoas negras sul-africanas seriam mesmo inimigas. "Então também percebi que, num país, uma coisa é o governo, outra coisa é o povo." (Bom dia camaradas, p. 28). Outros valores, outras perspectivas e outras realidades sociais constituem-se como elementos essenciais na jornada educativa do herói.

Outro elemento emblemático do rito de passagem dos heróis nos romances de formação, presente também no romance resenhado, é a expectativa social em forjar no menino um homem forte. Esse não pode mostrar fragilidades menino não chora:

Ê, hum!, tipo que o camarada professor Ángel também tinha lágrimas a escorregar no canto do olho. Nós batemos palmas; a camarada professora e a Petra estavam mesmo a chorar, a Ró não sei, não conseguia ver a cara dela, eu tinha ficado uns coche emocionado também, mas não podia bandeirar, o Cláudio estava atento (Bom dia camaradas, p. 113). 
As inquietações, as dúvidas, as perdas necessitam de mecanismos que auxiliam no abrandamento dos medos e da incompreensão em relação ao mundo real. E, nesse sentido, o devir, as metas, enfim, a perspectiva teleológica, se constitui também como objeto de escapismo:

Ao ver aquela tanta água, lembrei-me das redações que fazíamos sobre a chuva, o solo, a importância da água. Uma camarada professora que tinha a mania que era poeta dizia que a água é que traz todo aquele cheiro que a terra cheira depois de chover, a água é que faz crescer novas coisas na terra, embora também alimente as raízes dela, a água faz "eclodir um novo ciclo", enfim, ela queria dizer que a água faz o chão dar folhas novas. Então pensei: “Epá... E se chovesse aqui em Angola toda...?” Depois sorri. Sorri só (Bom dia camaradas, p. 137).

Não é só o menino que é iniciado nos mais diversos ritos de passagem, mas também Angola. É o desejo, talvez uma das metas do romance, por uma nova Angola (pressuposto teleológico). Dois "personagens" em sua jornada formativa.

Texto recebido em 19 de novembro de 2009

Texto aprovado em 26 de junho de 2010 